\title{
Melt-spun poly(tetrafluoroethylene) fibers
}

\author{
Matthias Goessi $\cdot$ Theo Tervoort $\cdot$ Paul Smith
}

Received: 14 August 2006/Accepted: 13 November 2006/Published online: 26 June 2007

(C) Springer Science+Business Media, LLC 2007

\begin{abstract}
The recent discovery of melt-processable poly(tetrafluoroethylene) (PTFE) allows for common thermoplastic-polymer processing technologies to be applied to this unique polymer, which heretofore was considered to be highly intractable. In this paper, we report simple meltspinning of monofilaments of a set of melt-processable (modified) PTFE grades with weight-average molar masses $\left(M_{\mathrm{w}}\right)$ ranging from 77 to $292 \mathrm{~kg} / \mathrm{mol}$. Fibers were spun at $380{ }^{\circ} \mathrm{C}$ at draw-down ratios of up to 2,750 , yielding filaments of linear densities as low as 0.8 tex, corresponding to a diameter of $\sim 20 \mu \mathrm{m}$. The maximum Young's modulus and tensile strength of as-spun fibers produced in this study were $91.7 \mathrm{cN} /$ tex $(1,972 \mathrm{MPa})$ and $12.0 \mathrm{cN} /$ tex $(258 \mathrm{MPa})$, respectively, accompanied by a strain to break of $24 \%$.
\end{abstract}

\section{Introduction}

Poly(tetrafluoroethylene) (PTFE) exhibits, among other unique characteristics, outstanding chemical and thermal resistance, low surface friction and high hydrophobicity and high fracture toughness, also at cryogenic temperatures. This exceptional combination of properties make PTFE a prime material for demanding fiber applications, such as industrial filters and the like, and water-repellant fabrics [1]. Unfortunately, due to its ultra-high weightaverage molar masses (typically $>10^{7} \mathrm{~g} / \mathrm{mol}$ ), standard PTFE grades have a very high melt viscosities, most often exceeding $10^{11} \mathrm{~Pa} \cdot \mathrm{s}$, which prohibits common thermo-

M. Goessi · T. Tervoort $(\bowtie) \cdot$ P. Smith

Department of Materials, ETH Zurich, 8093 Zurich, Switzerland

e-mail: theo.tervoort@mat.ethz.ch plastic-polymer processing techniques such as injection molding and melt spinning [1]. Due to the relatively intractable nature of common PTFE, present stateof-the-art industrial processes to manufacture fibers of this polymer are cumbersome and inefficient. These processes include the split-peel process (i.e. skiving from sintered preforms, which may take $48 \mathrm{~h}$ or more to produce), matrix spinning followed by sintering of PTFE and removal of the matrix material, and paste extrusion and sintering of the polymer [2-4]. The mechanical properties of the asproduced fibers most often are improved by subsequent tensile drawing techniques [see also 5, 6].

Recently, we demonstrated that for PTFE there exists a narrow range of molar masses that permits standard thermoplastic processing, while yielding products with good mechanical properties $[7,8]$. By blending high ("intractable") and low (brittle "micropowders") molar mass PTFE grades, bimodal grades with weight-average molar masses $\left(M_{\mathrm{w}}\right)$ between 500 and $1,000 \mathrm{~kg} / \mathrm{mol}$ were produced, which were found to be melt-processable and to exhibit tough behavior. More recently, we demonstrated that poly(tetrafluoroethylene)s of a narrow monomodal molar mass distribution with $M_{\mathrm{w}}$ between about 50 and $300 \mathrm{~kg} / \mathrm{mol}$ and comprising a minor amount of perfluoro(propylvinylether) (PPVE) (0.04 mol\% up to $0.5 \mathrm{~mol} \%$ ) provided an enhancement to optimize the delicate balance between processability and properties [9]. NB: according to ISO 12086, tetrafluoroethylene polymers with up to $1 \mathrm{wt} \%$ comonomer (0.4 mol\% PPVE) are referred to as (modified) PTFE homopolymer, unlike the commercial copolymers such as FEP [10] and PFA [11], which typically comprise, respectively, more than $5 \mathrm{~mol} \%$ of hexafluoropropylene and $1.5 \mathrm{~mol} \%$ perfluoro(propylvinylether), quantities that adversely affect a number of the desirable properties of the homopolymer [1]. 
The aim of this research was to demonstrate production of monofilaments of these novel melt-processable PTFE grades by melt-spinning and explore the dependence of the mechanical properties of the fibers on material and processing parameters.

\section{Experimental}

Materials

PTFE grades used in this study were kindly supplied by Dyneon $\mathrm{GmbH}$, Germany, and are listed in Table 1 according to increasing zero-shear viscosity. The PPVEcomonomer content and melt-flow index (MFI) were determined at Dyneon. The zero-shear viscosity and the molar mass distribution were determined in a separate study, which will be published elsewhere [9]. Melting temperatures were measured with differential scanning calorimetry (DSC; see below).

Fiber spinning

Monofilaments were spun at $380{ }^{\circ} \mathrm{C}$ employing the SpinLine from $\mathrm{DACA}^{\circledR}$ Instruments (Santa Barbara, CA) equipped with a dual elliptical radiant heater from RESEARCH INC. (Eden Prairie, MN), mounted between the spinneret and the take-up device (cf. Fig. 1). The air inside the chamber reached the temperature at half height. A similar setup was used by Uno et al. [4] for melt-spinning of fluorinated ethylene-propylene copolymer (FEP) fibers. Two spinnerets of different entrance angles and orifice lengths were used. As is customary, the draw-down ratio, $\lambda_{\mathrm{d}}$, applied during fiber spinning is defined as the ratio of the take-up speed $\left(v_{\text {take-up }}\right)$ and the extrusion speed $\left(v_{\text {extrusion }}\right)$ :

$\lambda_{\mathrm{d}}=\frac{v_{\text {take }- \text { up }}}{v_{\text {extrusion }}}$

\section{Characterization}

Mechanical testing was performed at room temperature with an Instron tensile tester (model 4411). The sample gauge length was $50 \mathrm{~mm}$ and the cross-head speed was $50 \mathrm{~mm} / \mathrm{min}$, which corresponds to an initial strain rate of $1 \mathrm{~min}^{-1}$. The mechanical properties and linear density were determined according to ASTM D 3822-96 and ASTM D 1577-96, respectively. Average values obtained in at least three tensile tests are reported here. Besides linear strain $\varepsilon$, in the following, deformation is also expressed in terms of the draw ratio $\lambda=\varepsilon+1$. The true specific stress was calculated by multiplying the engineering specific stress with the draw ratio, assuming constant volume during deformation.

Table 1 Melt-processable PTFE grades used and their PPVE-comonomer content, melt flow index determined at $372{ }^{\circ} \mathrm{C}$ and $10 \mathrm{~kg}$ load $(\mathrm{MFI}$ $372 / 10)$, zero-shear viscosity $\left(\eta^{*} 0\right)$ and weight-average $\left(M_{\mathrm{w}}\right)$ and number-average molar mass $\left(M_{\mathrm{n}}\right)$ (determined by rheology [9])

\begin{tabular}{|c|c|c|c|c|c|c|}
\hline PTFE grade & Zero-shear viscosity $(\mathrm{kPa} \cdot \mathrm{s})$ & MFI 372/10 (g/10 min) & $M_{\mathrm{w}}(\mathrm{kg} / \mathrm{mol})$ & $M_{\mathrm{n}}(\mathrm{kg} / \mathrm{mol})$ & PPVE-content (mol\%) & $T_{\mathrm{m}}\left({ }^{\circ} \mathrm{C}\right)$ \\
\hline I & 1.1 & 50 & 77 & 46 & 0.376 & 320 \\
\hline II & 3.1 & 24 & 108 & 68 & 0.226 & 323 \\
\hline III & 3.3 & 36 & 106 & 73 & 0.376 & 320 \\
\hline IV & 4.2 & 21 & 120 & 91 & 0.124 & 325 \\
\hline $\mathrm{V}$ & 4.6 & 16 & 119 & 79 & 0.226 & 323 \\
\hline VI & 19 & 4.0 & 177 & 111 & 0.391 & 318 \\
\hline VII & 20 & 3.6 & 181 & 121 & 0.293 & 321 \\
\hline VIII & 23 & 1.5 & 185 & 100 & 0.192 & 322 \\
\hline IX & 25 & 1.7 & 196 & 106 & 0.693 & 320 \\
\hline$X$ & 27 & 2.8 & 200 & 122 & 0.222 & 319 \\
\hline XI & 28 & 2.3 & 202 & 121 & 0.263 & 320 \\
\hline XII & 32 & 2.5 & 211 & 127 & 0.207 & 323 \\
\hline XIII & 38 & 0.9 & 216 & 128 & 0.034 & 329 \\
\hline XIV & 44 & 1.5 & 227 & 130 & 0.414 & 318 \\
\hline XV & 58 & 1.3 & 248 & 153 & 0.158 & 322 \\
\hline XVI & 72 & 1.1 & 280 & 134 & 0.252 & 320 \\
\hline XVII & 80 & 1.0 & 286 & 136 & 0.090 & 326 \\
\hline XVIII & 91 & 0.7 & 292 & 147 & 0.143 & 325 \\
\hline
\end{tabular}

$T_{\mathrm{m}}$ refers to the peak melting point of once molten material 
Fig. 1 Schematic of the meltspinning setup used, consisting of a piston extruder, an (optional) heater and a take-up device. Also shown are the shapes of the two spinnerets employed. Dimensions in $\mathrm{mm}$

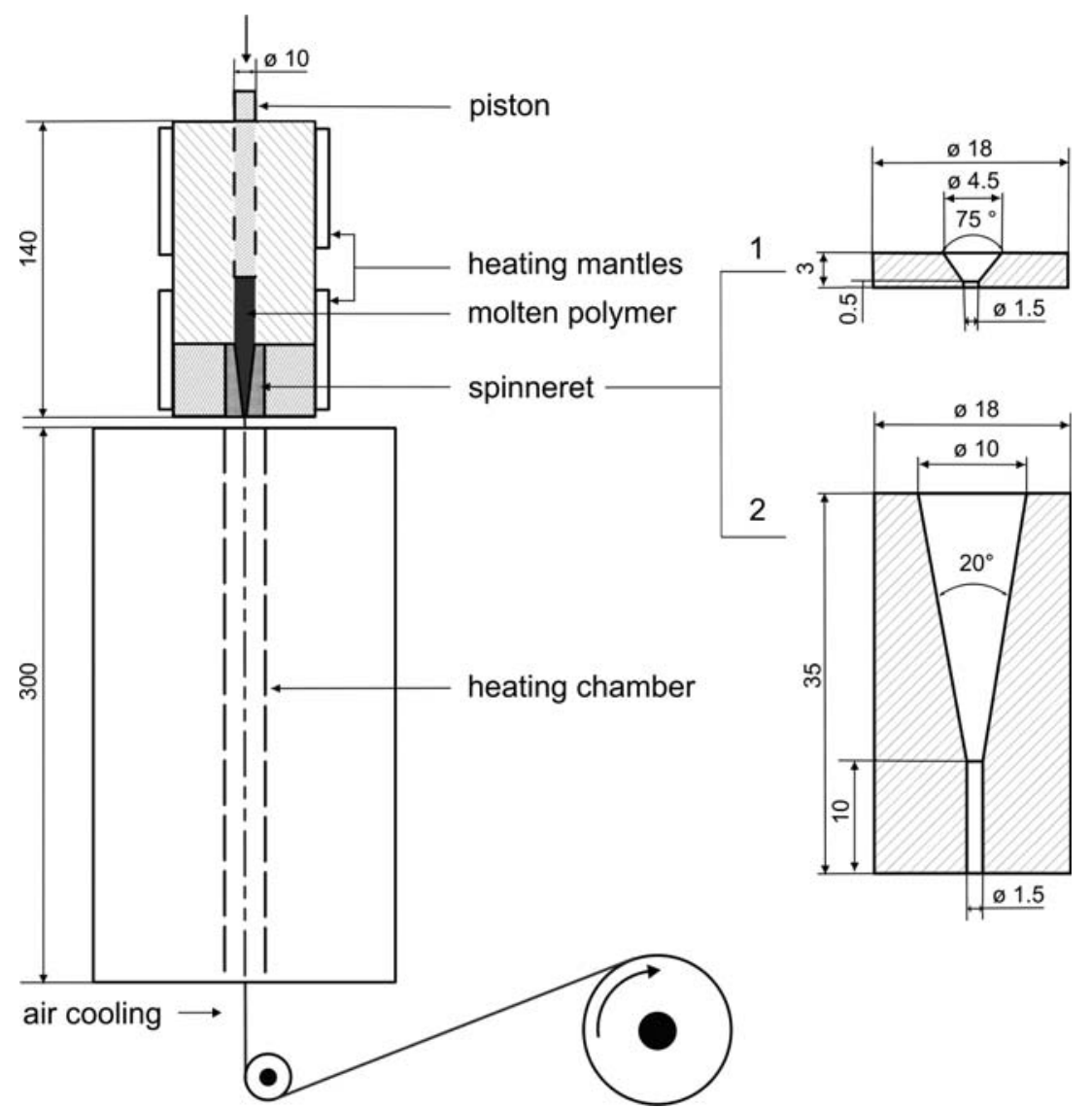

The effective draw ratio of the macromolecular network in the as-spun fibers $\left(\lambda_{\text {network }}\right)$ was determined from their true stress/draw ratio curves according to standard procedures [12]. In this method, the draw ratio axis is rescaled by multiplying with a factor $\left(\lambda_{\text {network }}\right)$ such that the stressstrain behavior immediately preceeding fracture optimally coincides with that of the isotropic material $\left(\lambda_{\text {network }}=1\right)$ of the same PTFE grade (see Fig. 6a).

Wide-angle X-ray analysis was carried out on single filaments with a Siemens rotating anode instrument (München, D), operated at $50 \mathrm{kV}$ and $80 \mathrm{~mA}$, equipped with a molybdenum target (focus $0.3 \mathrm{~mm} \times 0.3 \mathrm{~mm}$ ) and a Marresearch 300 image plate. Azimuthal integration was performed with Fit2D. The X-ray crystallinity was determined by deconvoluting the overlapping amorphous halo and the crystalline 100 diffraction peak [13, 14], as depicted in Fig. 2.

Differential scanning calorimetry (DSC) was conducted with a Mettler Toledo $822^{\mathrm{e}}$ instrument (Greifensee, $\mathrm{CH}$ ). Approximately $0.5 \mathrm{mg}$ of raw material or chopped fibers was heated at a rate of $10{ }^{\circ} \mathrm{C} / \mathrm{min}$ under nitrogen atmosphere. Melting temperatures $\left(T_{\mathrm{m}}\right)$ reported for isotropic materials refer to the endotherm peak temperatures of once molten (at $380{ }^{\circ} \mathrm{C}$ ) and cooled (at $10^{\circ} \mathrm{C} / \mathrm{min}$ ) material, whereas the melting temperatures of fibers were determined from the endotherms in the first heating scan.

\section{Results and discussion}

Extrusion behavior

With the present equipment and under the conditions here employed, PTFE grades with $M_{\mathrm{w}}<120 \mathrm{~kg} / \mathrm{mol}$, exhibiting a zero-shear viscosity $\left(\eta^{*}{ }_{0}\right)<4.6 \mathrm{kPa} \cdot \mathrm{s}$, could readily be extruded into smooth filaments at extrusion rates of $44.5 \mathrm{~mm} / \mathrm{min}$ using spinnerets 1 and 2 . In order to produce smooth extrudates of polymer grades with $M_{\mathrm{w}}$ between 160 and $227 \mathrm{~kg} / \mathrm{mol}\left(18.6 \mathrm{kPa} \cdot \mathrm{s}<\eta^{*_{0}}<43.6 \mathrm{kPa} \cdot \mathrm{s}\right)$, spinneret 2 had to be employed and the extrusion rate needed to be reduced to $4.5 \mathrm{~mm} / \mathrm{min}$. PTFE grades with $M_{\mathrm{w}}>227$ $\mathrm{kg} / \mathrm{mol}\left(\eta^{*}{ }_{0}>43.6 \mathrm{kPa} \cdot \mathrm{s}\right)$ could not be continuously and smoothly extruded with the current setup. An overview of the behavior of these three different polymer grade groups is shown in Fig. 3. From this figure, it is evident that the extrusion behavior is dominated by the molar mass of the PTFE grades only; no influence of the comonomer content on the melt-flow behavior was detected. 


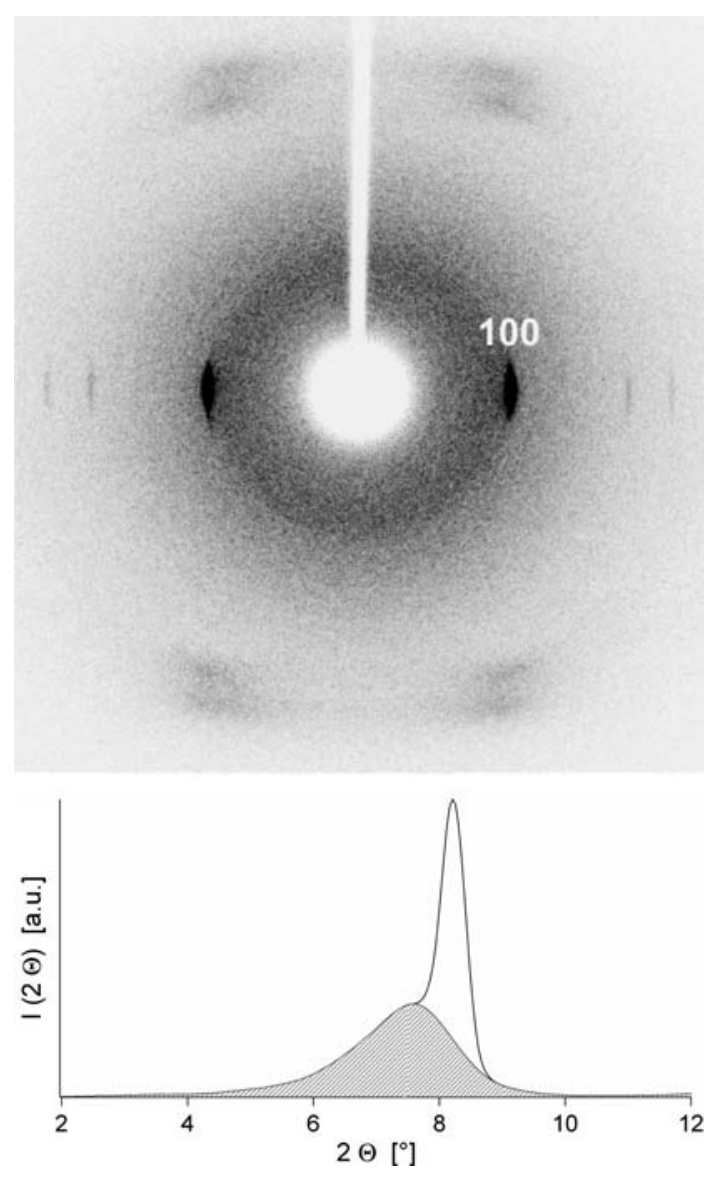

Fig. 2 Wide-angle X-ray scattering pattern of a melt-spun fiber of PTFE grade IX, spun at a draw-down ratio of 350 and a chamber temperature of $300{ }^{\circ} \mathrm{C}$ using spinneret 2 (top; fiber axis vertical). Determination of the degree of crystallinity was performed on azimuthal-integrated patterns (bottom) by deconvoluting the overlapping amorphous halo (shaded area) and 100 diffraction peak

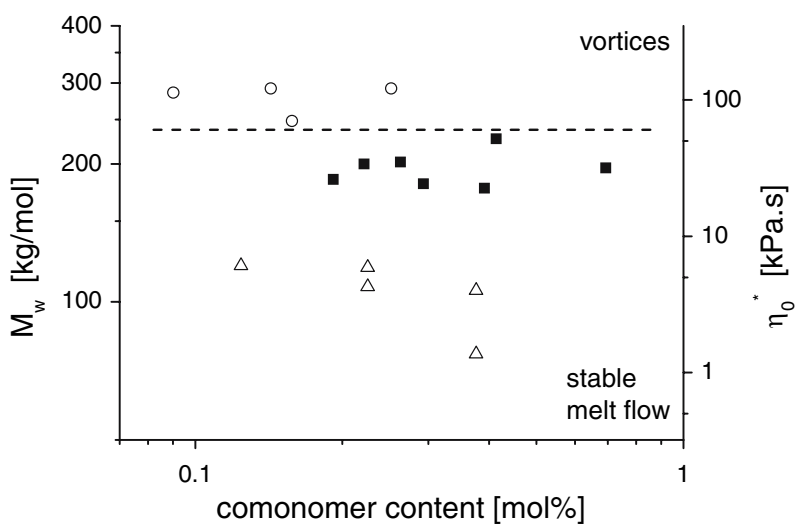

Fig. 3 "Map" of melt flow of PTFE grades. Materials with $M_{\mathrm{w}}>227 \mathrm{~kg} / \mathrm{mol}(\mathrm{O}$; XV-XVIII) could not be extruded in a satisfactory manner with the spinnerets shown in Fig. 1 at piston speeds exceeding $0.1 \mathrm{~mm} / \mathrm{min}$. Grades with $M_{\mathrm{w}}$ in the range of 160 $227 \mathrm{~kg} / \mathrm{mol}$ (匹; VI-XIV), by contrast, could be continuously extruded into smooth filaments at a piston speed of $0.1 \mathrm{~mm} / \mathrm{min}$ employing spinneret 2 , and those of $79-120 \mathrm{~kg} / \mathrm{mol}(\triangle$; I-V) with both spinnerets 1 and 2 at $380{ }^{\circ} \mathrm{C}$ at a piston speed of $1 \mathrm{~mm} / \mathrm{min}$
Depending on the extrusion rate, three different types of extrudates were obtained, characteristic of different extrusion phenomena. High extrusion rates lead to "wall slip", where the molten polymer no longer flowed as a viscous fluid, but rather slipped as a solid block with no velocity gradient across the diameter of the extrusion tube leading to an irregular, rough surface (cf. Fig. 4a, sample IX, extruded at a rate of $1,335 \mathrm{~mm} / \mathrm{min}$ with spinneret 2 ). Medium extrusion rates resulted in the formation of vortices in the melt, caused by the taper of the spinneret, yielding an extrudate of a screw-like geometry (Fig. 4b, $356 \mathrm{~mm} / \mathrm{min}$ ). The vortex in the melt, and therefore the pitch of the screw-like extrudate, depended on the geometry of the spinneret and the speed of extrusion, with the pitch decreasing with decreasing extrusion rate. An elegant model describing the formation of such vortices was advanced by Bulters and Meijer [15]. In order to obtain extrudates with smooth surfaces, the extrusion rate was required to be low and abrupt geometry changes in the spinneret had to be avoided. For the above-referred sample IX, shown in Fig. 4c, the extrusion rate needed to be $22 \mathrm{~mm} / \mathrm{min}$ or below, also when using spinneret 2 .

It is well known that, in the absence of a pulling force provided by the take-up, extruded polymer melts may relax after leaving the spinneret leading to an extrudate diameter that exceeds the diameter of the orifice. This phenomenon, commonly referred to as "die swell", was not observed for any of the melt-processable PTFE grades. The diameter of the extrudate always was the same as that of the orifice, possibly due to low friction between the polymer melt and the extruder wall, which is characteristic for perfluorinated polymers.

\section{Draw-down behavior}

Drawing down of extrudates that exhibited instable melt flow invariably resulted in filament breakage. For smooth extrudates, the maximum draw-down ratio, $\lambda_{\mathrm{d} \text {,max }}$, before filament fracture occurred was found to decrease with increasing $M_{\mathrm{w}}$, as shown in Fig. 5a, and was hardly influenced by the comonomer content.

Assuming conservation of volume during the spinning process, the linear density of an as-spun fiber equals the linear density of the extrudate divided by the applied drawdown ratio, and is, thus, uniquely determined by it, as shown in Fig. 5b. Hence, under identical spinning conditions, the molar mass determined the minimum linear density through limitation of $\lambda_{\mathrm{d} \text {,max }}$.

A summary of typical experimental conditions for successful melt-spinning (heating chamber at RT) of PTFE grades with $M_{\mathrm{w}}<227 \mathrm{~kg} / \mathrm{mol}$ and selected properties of the monofilaments produced is given in Table 2. These data show that with the simple laboratory equipment here 
Fig. 4 Extrudates of PTFE grade IX produced at $380{ }^{\circ} \mathrm{C}$ without draw down with spinneret 2 at extrusion rates of $1,335 \mathrm{~mm} / \mathrm{min}$ (a), $356 \mathrm{~mm} /$ min (b) and $22 \mathrm{~mm} / \mathrm{min}$ (c). The irregular shapes of extrudates (a) and (b) are the result of perturbed flow of the molten polymer due to wall slip and vortices, respectively. Photomicrographs in left panels taken with reflected light; right, in transmission with crossed polarizers (a)
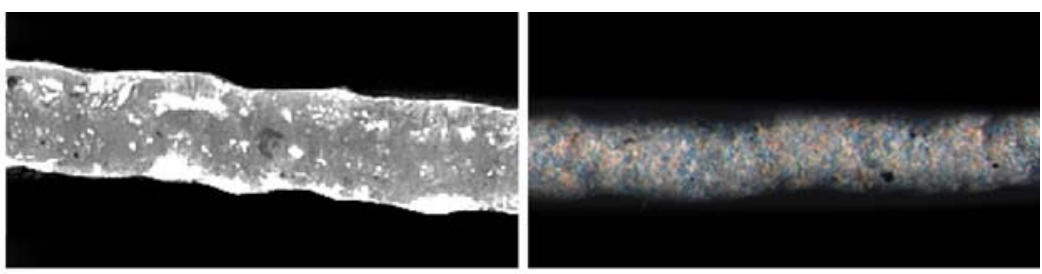

(b)
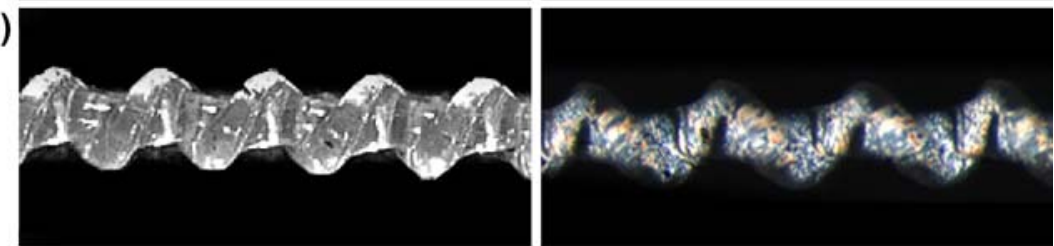

(c)

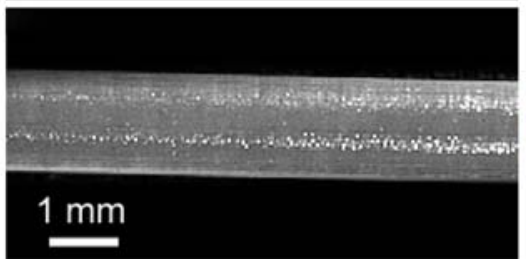

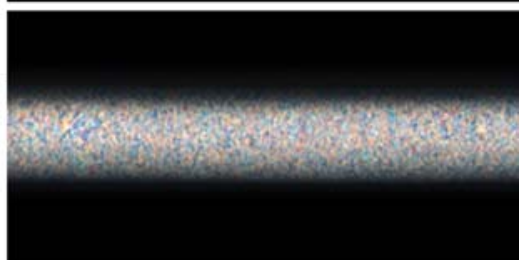
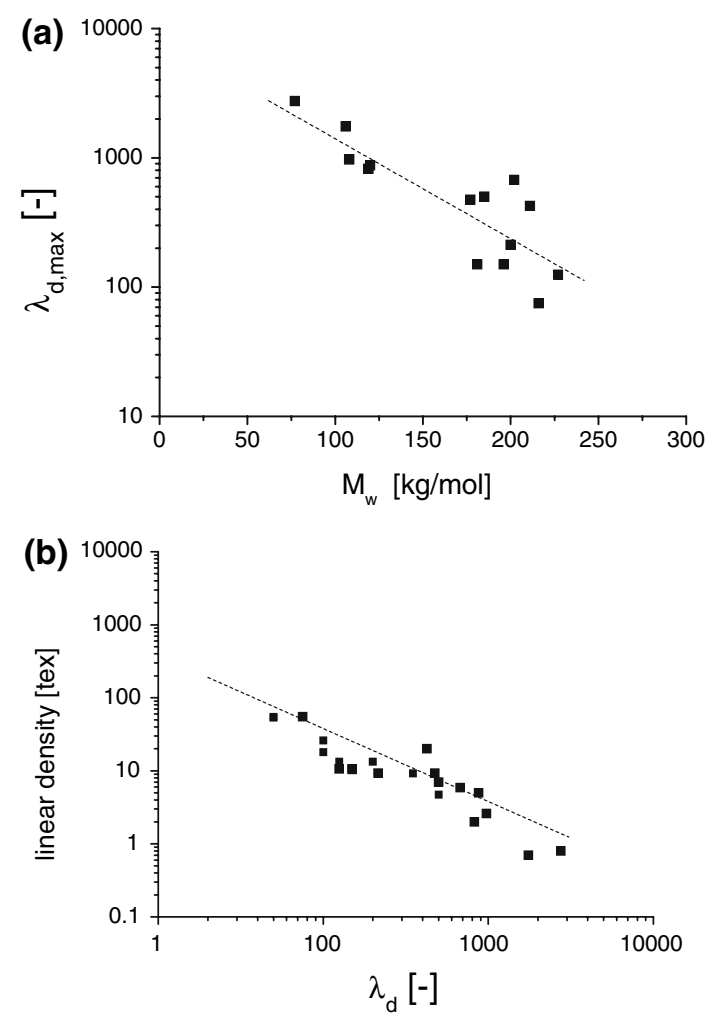

Fig. 5 (a) Maximum draw-down ratio, $\lambda_{\text {d, max }}$, versus the weightaverage molar mass $M_{\mathrm{w}}$ of different melt-processable PTFE grades. The dotted line is a guide to the eye only. (b) Linear density as a function of $\lambda_{\mathrm{d}}$. Dotted line calculated assuming constant volume during spinning

used, fine PTFE monofilaments could be spun at drawdown ratios of up to 2,750 , corresponding to a take-up speed of $112 \mathrm{~m} / \mathrm{min}$.
Relation between mechanical properties and processing conditions

The relation between the processing conditions and resulting mechanical properties of as-spun fibers was examined in more detail for PTFE grade IX $\left(M_{\mathrm{w}}=196 \mathrm{~kg} / \mathrm{mol}\right.$, comonomer content $0.693 \mathrm{~mol} \%$ ). The draw-down ratio was widely varied and the temperature of the heating chamber between the spinneret and the take-up device was set to either room temperature or $300{ }^{\circ} \mathrm{C}$. An overview of the processing conditions and mechanical properties, linear densities, X-ray crystallinities, network draw ratios and melting temperatures of the PTFE monofilaments produced is given in Table 3 .

As is well known, and found to be true also for the present melt-spun PTFE filaments, the mechanical properties of as-spun fibers are mainly determined by its molar mass and the degree of uniaxial orientation of the macromolecular chains. That orientation originates in the deformation of the molecular network expressed by the network draw ratio ( $\left.\lambda_{\text {network }}\right)$. The dependency of the network draw ratio on two important processing parameters, i.e. draw-down ratio $\left(\lambda_{\mathrm{d}}\right)$ and heating chamber temperature, is shown in Fig. 6b. Quenching the extruded monofilaments directly to room temperature caused $\lambda_{\text {network }}$ to increase more rapidly with $\lambda_{\mathrm{d}}$ than when the chamber temperature was $300{ }^{\circ} \mathrm{C}$, due to a shorter period of time for macromolecular relaxation in the former case. The benefit of a high chamber temperature, on the other hand, was that it permitted spinning of filaments of lower linear densities.

Not unexpectedly, it was found that the specific Young's modulus was uniquely dependent on the network draw ratio 
Table 2 Experimental conditions of melt-spinning of PTFE monofilaments: spinneret, extrusion rate and maximum draw-down ratio $\left(\lambda_{\mathrm{d}, m a x}\right)$ and corresponding maximum values of Young's modulus $(E)$, tensile strength $\left(\sigma_{\mathrm{B}}\right)$ and strain to break $\left(\varepsilon_{\mathrm{B}}\right)$

\begin{tabular}{|c|c|c|c|c|c|c|c|c|c|}
\hline \multirow{2}{*}{$\begin{array}{l}\text { PTFE } \\
\text { grade }\end{array}$} & \multirow[t]{2}{*}{ Spinneret } & \multirow{2}{*}{$\begin{array}{l}\text { Extrusion rate } \\
(\mathrm{mm} / \mathrm{min})\end{array}$} & \multirow{2}{*}{$\begin{array}{l}\lambda_{\mathrm{d}, \max } \\
(-)\end{array}$} & \multirow{2}{*}{$\begin{array}{l}\text { Linear density } \\
\text { (tex) }\end{array}$} & \multicolumn{2}{|l|}{$E$} & \multicolumn{2}{|l|}{$\sigma_{\mathrm{B}}$} & \multirow{2}{*}{$\begin{array}{l}\varepsilon_{\mathrm{B}} \\
(\%)\end{array}$} \\
\hline & & & & & $(\mathrm{cN} /$ tex $)$ & (MPa) & (cN/tex) & (MPa) & \\
\hline I & 1 & 44.5 & 2,750 & 0.8 & 18 & 387 & 0.9 & 19 & 51 \\
\hline II & 1 & 44.5 & 975 & 2.6 & 26 & 559 & 2.6 & 56 & 47 \\
\hline III & 1 & 44.5 & 1,750 & 0.7 & 33 & 710 & 5.4 & 116 & 37 \\
\hline IV & 1 & 44.5 & 875 & 5.0 & 29 & 624 & 1.8 & 39 & 11 \\
\hline V & 1 & 44.5 & 825 & 2.0 & 60 & 1,290 & 5.5 & 118 & 72 \\
\hline VI & 2 & 4.5 & 475 & 9.3 & 57 & 1,226 & 7.6 & 163 & 48 \\
\hline VII & 2 & 4.5 & 150 & 10.6 & 48 & 1,032 & 5.9 & 127 & 30 \\
\hline VIII & 2 & 4.5 & 500 & 7.0 & 60 & 1,290 & 8.1 & 174 & 35 \\
\hline IX & 2 & 4.5 & 150 & 10.5 & 77 & 1,656 & 8.2 & 176 & 29 \\
\hline$X$ & 2 & 4.5 & 215 & 9.3 & 33 & 710 & 5.8 & 125 & 29 \\
\hline XI & 2 & 4.5 & 675 & 5.9 & 44 & 946 & 5.7 & 123 & 27 \\
\hline XII & 2 & 4.5 & 425 & 20.0 & 19 & 409 & 1.7 & 37 & 82 \\
\hline XIII & 2 & 4.5 & 75 & 55.2 & 29 & 624 & 1.0 & 22 & 66 \\
\hline XIV & 2 & 4.5 & 125 & 10.6 & 57 & 1,226 & 8.3 & 178 & 35 \\
\hline
\end{tabular}

The chamber was kept at room temperature

Table 3 Young's modulus $(E)$, tensile strength $\left(\sigma_{\mathrm{B}}\right)$, strain to break $\left(\varepsilon_{\mathrm{B}}\right)$, linear density, X-ray crystallinity $\left(\emptyset_{\mathrm{c}} \mathrm{X}\right.$-ray $)$, network draw ratio $\left(\lambda_{\text {network }}\right)$ and melting temperature $\left(T_{\mathrm{m}}\right)$ of monofilaments of PTFE grade IX, spun at chamber temperatures of RT or $300{ }^{\circ} \mathrm{C}$ at the indicated draw-down ratios $\left(\lambda_{\mathrm{d}}\right)$ using spinneret 2

\begin{tabular}{|c|c|c|c|c|c|c|c|c|c|c|}
\hline \multirow{2}{*}{$\begin{array}{l}\text { Chamber temperature } \\
\left({ }^{\circ} \mathrm{C}\right)\end{array}$} & \multirow{2}{*}{$\begin{array}{l}\lambda_{\mathrm{d}} \\
(-)\end{array}$} & \multicolumn{2}{|l|}{$E$} & \multicolumn{2}{|l|}{$\sigma_{\mathrm{B}}$} & \multirow{2}{*}{$\begin{array}{l}\varepsilon_{\mathrm{B}} \\
(\%)\end{array}$} & \multirow{2}{*}{$\begin{array}{l}\text { Linear density } \\
\text { (tex) }\end{array}$} & \multirow{2}{*}{$\begin{array}{l}\emptyset_{\mathrm{c} X \text { X-ray }} \\
(\%)\end{array}$} & \multirow{2}{*}{$\begin{array}{l}\lambda_{\text {network }} \\
(-)\end{array}$} & \multirow{2}{*}{$\begin{array}{l}T_{\mathrm{m}} \\
\left({ }^{\circ} \mathrm{C}\right)\end{array}$} \\
\hline & & $(\mathrm{cN} / \mathrm{tex})$ & (MPa) & $(\mathrm{cN} / \mathrm{tex})$ & (MPa) & & & & & \\
\hline $\mathrm{RT}$ & 50 & $19.8 \pm 0.2$ & $426 \pm 4$ & $3.5 \pm 0.2$ & $75 \pm 4$ & $183 \pm 23$ & 53.2 & 28 & 2.17 & 316 \\
\hline RT & 100 & $42.9 \pm 5.3$ & $922 \pm 114$ & $8.5 \pm 1.2$ & $183 \pm 26$ & $80 \pm 6$ & 18.0 & 35 & 3.88 & 318 \\
\hline $\mathrm{RT}$ & 125 & $56.0 \pm 1.3$ & $1204 \pm 28$ & $8.7 \pm 0.7$ & $187 \pm 15$ & $53 \pm 9$ & 13.3 & 36 & 4.51 & 320 \\
\hline $\mathrm{RT}$ & 150 & $77.0 \pm 0.7$ & $1656 \pm 5$ & $8.2 \pm 0.9$ & $176 \pm 19$ & $29 \pm 9$ & 10.5 & 42 & 4.98 & 322 \\
\hline 300 & 50 & $17.6 \pm 0.1$ & $378 \pm 2$ & $2.8 \pm 0.1$ & $60 \pm 2$ & $240 \pm 9$ & 54.7 & 33 & 1.72 & 316 \\
\hline 300 & 100 & $26.0 \pm 1.9$ & $559 \pm 41$ & $4.9 \pm 0.2$ & $105 \pm 4$ & $165 \pm 10$ & 26.0 & 34 & 2.60 & 316 \\
\hline 300 & 200 & $50.3 \pm 2.4$ & $1081 \pm 52$ & $7.7 \pm 0.3$ & $166 \pm 6$ & $57 \pm 6$ & 13.3 & 39 & 4.27 & 321 \\
\hline 300 & 350 & $64.7 \pm 3.3$ & $1391 \pm 71$ & $8.5 \pm 0.6$ & $183 \pm 13$ & $40 \pm 7$ & 9.2 & 43 & 4.78 & 323 \\
\hline 300 & 500 & $91.7 \pm 3.3$ & $1972 \pm 71$ & $12.0 \pm 0.6$ & $258 \pm 13$ & $24 \pm 5$ & 4.7 & 36 & 5.92 & 320 \\
\hline
\end{tabular}

and not on the chamber temperature, as shown in Fig. 6c. The maximum achieved specific Young's modulus was $91.7 \mathrm{cN} /$ tex, or $1,972 \mathrm{MPa}$, at a network draw ratio of $\sim 6$.

The well-known development of the Young's modulus with (network) draw ratio [16-18] was evaluated with the simple model advanced by Irvine and Smith [19]. In this model, a polymeric material is assumed to consist solely of fully oriented segments with a Young's modulus $E_{\mathrm{c}}$ and unoriented segments with modulus $E_{\mathrm{u}}$, whereby the fraction of fully oriented segments equals the Herman's orientation factor $f_{\mathrm{h}}$. In the case of constant stress [18, 19], the Young's modulus $E$ of an uniaxially oriented polymer is given by:
$\frac{1}{E}=\frac{f_{\mathrm{h}}}{E_{\mathrm{c}}}+\frac{1-f_{\mathrm{h}}}{E_{\mathrm{u}}}$

Assuming pseudo-affine deformation, the Herman's orientation function is only dependent on the draw ratio as:

$$
\begin{aligned}
f_{\mathrm{h}}= & \frac{\left(3 \overline{\cos ^{2} \chi}-1\right)}{2}=\frac{3 \lambda^{3}}{2\left(\lambda^{3}-1\right)} \\
& -\frac{3}{2}\left(\frac{\lambda^{3}}{\left(\lambda^{3}-1\right)^{3 / 2}} \cdot \operatorname{atan} \sqrt{\lambda^{3}-1}\right)-\frac{1}{2}
\end{aligned}
$$



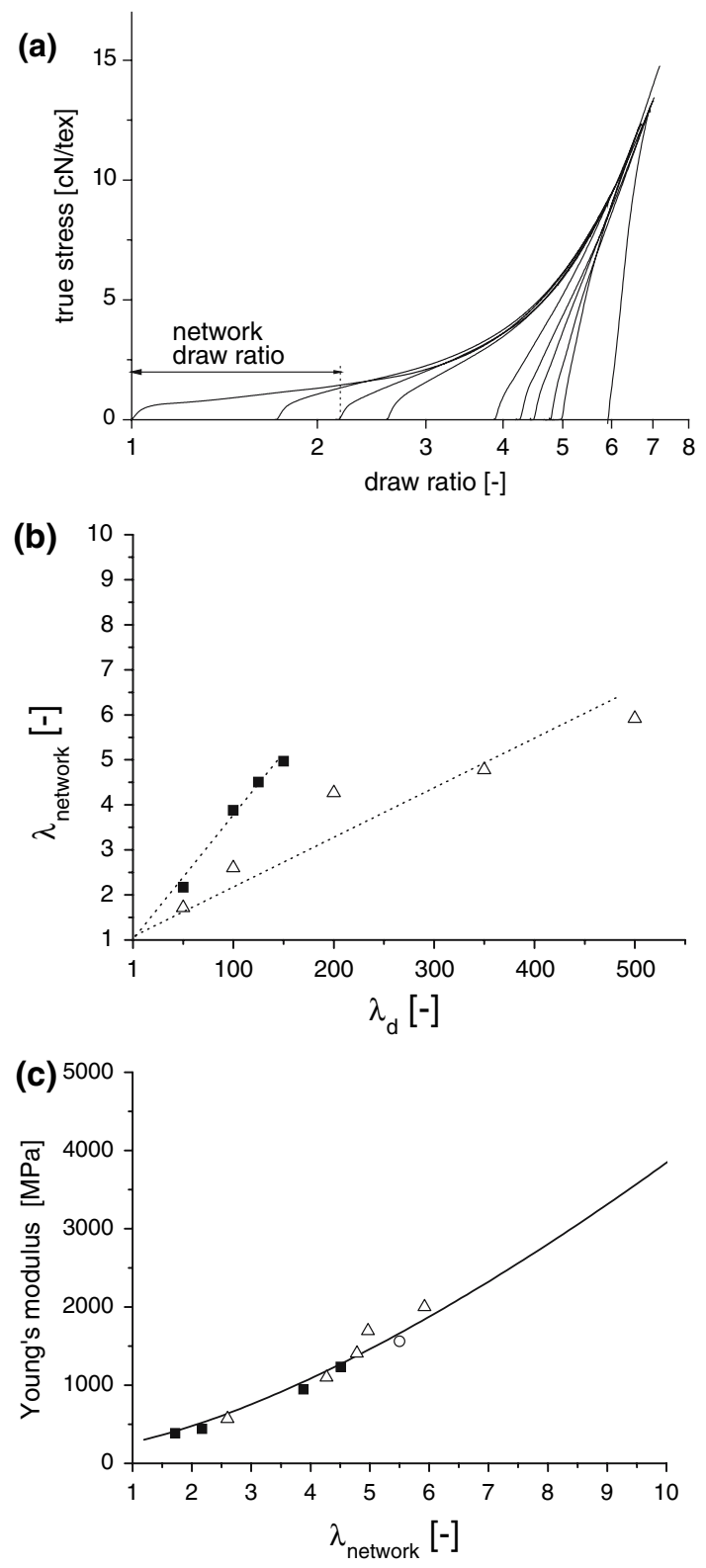

Fig. 6 (a) True stress $\left(\sigma_{\text {true }}\right)$-draw ratio $(\lambda)$ curves of as-spun fibers produced at different draw-down ratios listed in Table 3, as well as of isotropic material of grade IX (bold). The $\sigma_{\text {true }}-\lambda$ curves of the asspun fibers were shifted horizontally toward that of the isotropic material by multiplying $\lambda$ by the network draw ratio $\left(\lambda_{\text {network }}\right.$, see text). (b) $\lambda_{\text {network }}$ versus draw-down ratio $\left(\lambda_{\mathrm{d}}\right)$ for fibers spun at heating-chamber-temperatures of RT $(\square)$ and $300{ }^{\circ} \mathrm{C}(\triangle)$, respectively. (c) Young's modulus of the as-spun fibers in (b) as a function of $\lambda_{\text {network}}$. The solid line was calculated with Eq. 4 with $E_{\mathrm{u}}=300 \mathrm{MPa}$ and $E_{\mathrm{c}}=158 \mathrm{GPa}$ [5]. The open circle represents the Young's modulus of compression-molded, isotropic material of grade IX drawn to $\lambda$ of 5.5 at $250{ }^{\circ} \mathrm{C}$

where $\chi$ is the angle between the direction of the chain vector and the drawing direction. Substitution of Eq. 3 in 2 yields the development of the Young's modulus with the draw ratio:

$$
\begin{aligned}
E= & {\left[E_{\mathrm{u}}^{-1}-\left(\left(\frac{3 \lambda^{3}}{2\left(\lambda^{3}-1\right)}-\frac{3}{2}\left(\frac{\lambda^{3}}{\left(\lambda^{3}-1\right)^{3 / 2}}\right.\right.\right.\right.} \\
& \left.\left.\left.\left.\cdot \operatorname{atan} \sqrt{\lambda^{3}-1}\right)-\frac{1}{2}\right) \cdot\left(E_{\mathrm{u}}^{-1}-E_{\mathrm{c}}^{-1}\right)\right)\right]^{-1}
\end{aligned}
$$

The modulus as a function of the network draw ratio for PTFE grade IX is presented in Fig. 6c. The solid line was calculated with Eq. 4, with $E_{\mathrm{c}}=158 \mathrm{GPa}$ [5] and $E_{\mathrm{u}}=300 \mathrm{MPa}$, which is the stiffness of unoriented PTFE, yielding gratifying accord with the experimental results when represented in terms of $\lambda_{\text {network}}$.

The fibers spun at the maximum draw-down ratio exhibited a tensile strength $\sigma_{\mathrm{B}}$ of $12.0 \mathrm{cN} / \mathrm{tex}(258 \mathrm{MPa})$ and a Young's modulus $E$ of $91.7 \mathrm{cN} /$ tex $(1,972 \mathrm{MPa})$, considerably exceeding the properties of melt-spun FEP fibers $\left(\sigma_{\mathrm{B}}=8.8 \mathrm{cN} / \mathrm{tex}, \quad 190 \mathrm{MPa} ; \quad E=65 \mathrm{cN} / \mathrm{tex}\right.$, 1,400 MPa) [20], and approaching those of melt-spun PFA fibers $\left(\sigma_{\mathrm{B}}=13.0 \mathrm{cN} /\right.$ tex,$\quad 280 \mathrm{MPa} ; \quad E=158 \mathrm{cN} / \mathrm{tex}$, 3,400 MPa) [20]. Not surprisingly, paste-extruded fibers of common PTFE, e.g. Gore ${ }^{\mathrm{TM}}$ Rastex $^{\circledR} 4300\left(\sigma_{\mathrm{B}}=36.0\right.$ cN/tex, $775 \mathrm{MPa} ; E=170 \mathrm{cN} / \mathrm{tex}, 3,650 \mathrm{MPa}$ ), have a significantly higher tensile strength due to the ultra-high molecular mass of the polymer and a higher stiffness, due to a higher degree of orientation. A drawback of the latter fibers, however, is their relatively high linear density, which is 38 tex for Gore ${ }^{\mathrm{TM}}$ Rastex $^{\circledR} 4300$, i.e. more than 40 times higher than that of melt-spun FEP, PFA and PTFE fibers of $\sim 1$ tex $[4,20]$. In addition, melt-spun fibers have a highly regular cross-section and a smooth surface. The
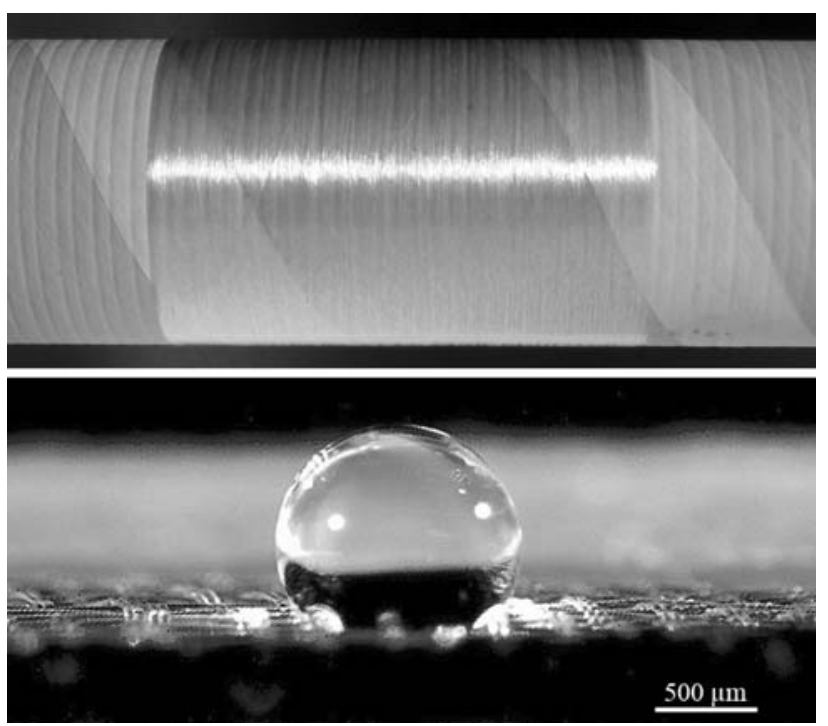

Fig. 7 Typical melt-spun monofilament of PTFE grade IX and a woven fabric produced thereof at 2,500 wefts/min, carrying a droplet of water, once more illustrating the extraordinary hydrophobic character of PTFE 
above mechanical properties of the present melt-spun PTFE filaments were sufficient to allow for weaving at a speed of 2,500 wefts per minute on industrial equipment. The resulting fabric was transparent and highly hydrophobic (cf. Fig. 7).

Acknowledgments Samples were provided by Dr. F. Kloos and Dr. G. Löhr (Dyneon, Germany). The authors are grateful for stimulating discussions with Prof. Dr. Ir. H.E.H. Meijer (Eindhoven University of Technology, The Netherlands), as well as for the experimental assistance of Messrs. Marco Sigrist and Raphael Heeb (ETH Zürich).

\section{References}

1. Scheirs J (1997) Modern fluoropolymers. John Wiley and Sons, NY

2. Berry KL (1951) US Patent 2,559,750

3. Monocrieff RW (1966) Man-made fibers. John Wiley and Sons, NY, p 512
4. Uno T, Miyata S, Shirai H (2002) J Appl Polym Sci 84:2366

5. Endo R, Kanamoto T (2001) J Polym Sci Polym Phys Ed 39:1995

6. Shimizu M, Ikeda C, Matsuo M (1996) Macromolecules 29:6724

7. Smith $\mathrm{P}$, Visjager J, Bastiaansen C, Tervoort T, US Patent 6,531,559 (2003); US Patent 6,548,612 (2003); US Patent $6,737,165$ (2004)

8. Tervoort T, Visjager J, Graf B, Smith P (2000) Macromolecules 33:6460

9. Goessi M, Tervoort T, Smith P, Characterization of Melt-processable Poly(tetrafluoroethylene) (to be published)

10. Bro MI, Sandt BW (1960) US Patent 2,946,763

11. Harris JF, McCane DI (1964) US Patent 3,132,123

12. Long SD, Ward IM (1991) J Appl Polym Sci 42:1911

13. Kilian HG, Jenkel E (1959) Z Elektrochem 63:308

14. Starkweather HW Jr, Clark ES (1962) J Appl Polym Sci 24:41

15. Bulters MJH, Meijer HEH (1990) J Non-Newton Fluid Mech 38:43

16. Crawford SM, Kolsky H (1951) Proc Phys Soc B 64:119

17. Grün F, Kuhn W (1942) Kolloid Z 101:248

18. Ward IM (1997) Structure and properties of oriented polymers, 2nd edn. John Wiley and Sons, NY, p 37

19. Irvine PA, Smith $P$ (1986) Macromolecules 19:240

20. Heffner GW, Uy WC, Wagner MG (2001) US Patent 6,207,275 